Louisiana State University

LSU Digital Commons

$10-1-2012$

\title{
Long-Term Survival of Anoxia Despite Rapid ATP Decline in Embryos of the Annual Killifish Austrofundulus limnaeus
}

\author{
Jason E. Podrabsky \\ Portland State University \\ Michael A. Menze \\ Eastern Illinois University \\ Steven C. Hand \\ Louisiana State University
}

Follow this and additional works at: https://digitalcommons.Isu.edu/biosci_pubs

\section{Recommended Citation}

Podrabsky, J., Menze, M., \& Hand, S. (2012). Long-Term Survival of Anoxia Despite Rapid ATP Decline in Embryos of the Annual Killifish Austrofundulus limnaeus. Journal of Experimental Zoology Part A:

Ecological Genetics and Physiology, 317 (8), 524-532. https://doi.org/10.1002/jez.1744

This Article is brought to you for free and open access by the Department of Biological Sciences at LSU Digital Commons. It has been accepted for inclusion in Faculty Publications by an authorized administrator of LSU Digital Commons. For more information, please contact ir@lsu.edu. 
Eastern Illinois University

The Keep

Faculty Research \& Creative Activity

Biological Sciences

August 2012

\section{Long-Term Survival of Anoxia Despite Rapid ATP Decline in Embryos of the Annual Killifish Austrofundulus limnaeus}

Jason E. Podrabsky

Portland State University

Michael A. Menze

Eastern Illinois University, michael.menze@louisville.edu

Steven C. Hand

Louisiana State University

Follow this and additional works at: http://thekeep.eiu.edu/bio_fac

Part of the Biology Commons, Cellular and Molecular Physiology Commons, and the Systems and Integrative Physiology Commons

\section{Recommended Citation}

Podrabsky, Jason E.; Menze, Michael A.; and Hand, Steven C., "Long-Term Survival of Anoxia Despite Rapid ATP Decline in Embryos of the Annual Killifish Austrofundulus limnaeus" (2012). Faculty Research \& Creative Activity. 92.

http://thekeep.eiu.edu/bio_fac/92

This Article is brought to you for free and open access by the Biological Sciences at The Keep. It has been accepted for inclusion in Faculty Research \& Creative Activity by an authorized administrator of The Keep. For more information, please contact tabruns@eiu.edu. 
Long-Term Survival of Anoxia Despite Rapid ATP Decline in Embryos of the Annual Killifish Austrofundulus limnaeus

\author{
JASON E. PODRABSKY ${ }^{1 *}$, MICHAEL A. MENZE ${ }^{2}$, \\ AND STEVEN C. HAND ${ }^{3}$ \\ ${ }^{1}$ Department of Biology, Portland State University, Portland, Oregon \\ ${ }^{2}$ Department of Biological Sciences, Eastern Illinois University, Charleston, Illinois \\ ${ }^{3}$ Department of Biological Sciences, Louisiana State University, Baton Rouge, Louisiana
}

\begin{tabular}{ll} 
ABSTRACT & Embryos of the annual killifish Austrofundulus limnaeus can survive for months in the complete \\
absence of oxygen. Survival of anoxia is associated with entry into a state of metabolic dormancy \\
known as diapause. However, extreme tolerance of anoxia is retained for several days of post- \\
diapause development. Rates of heat dissipation in diapause II and 4 days post-diapause II embryos \\
were measured under aerobic conditions and during the transition into anoxia. Phosphorylated \\
adenylate compounds were quantified in embryos during entry into anoxia and after 12 hr of \\
aerobic recovery. Rates of heat dissipation were not affected by exposure to anoxia in diapause II \\
embryos, while post-diapause II embryos experienced a profound decrease in heat dissipation. ATP \\
decreased substantially in both developmental stages upon exposure to anoxia, and all indicators of \\
cellular energetic status indicated energetic stress, at least based on the mammalian paradigm. The \\
rate of decline in ATP is the most acute reported for any vertebrate. The mechanisms responsible for \\
cellular survival despite a clear dysregulation between energy production and energy consumption \\
remain to be identified. Necrotic and apoptotic cell death in response to hypoxia contribute to poor \\
survival during many diseases and pathological conditions in mammals. Understanding the \\
mechanisms that are in place to prevent maladaptive cell death in embryos of A. limnaeus may \\
greatly improve treatment strategies in diseases that involve hypoxia and reperfusion injuries. \\
J. Exp. Zool. 9999A:1-9, 2012. @ 2012 Wiley Periodicals, Inc. \\
\hline $\begin{array}{l}\text { How to cite this article: Podrabsky JE, Menze MA, Hand SC. 2012. Long-term survival of anoxia } \\
\text { despite rapid ATP decline in embryos of the annual killifish Austrofundulus limnaeus. J. Exp. Zool. }\end{array}$ \\
9999A:1-9.
\end{tabular}

In the majority of animals studied, entrance into a reversible metabolic arrest requires a coordinated downregulation of ATP producing and ATP consuming processes, such that the overall energetic status of cells is not severely compromised during the initial transition into dormancy (Hochachka, '86; Storey and Storey, '90; Hochachka et al., '96). This phenomenon is certainly the case for brain tissue in the few vertebrate species that can survive prolonged sojourns without oxygen (Nilsson and Lutz, 2004). While ATP concentration may decrease in other tissues in response to anoxia or hypoxia (e.g., Jibb and Richards, 2008; Stecyk et al., 2009), defense of cellular concentrations of ATP during the initial transition into oxygen deprivation is the rule rather than the exception, and is one of the major tenets proposed by Hochachka as the biochemical basis for survival in response to oxygen deprivation. Embryos of the annual killifish Austrofundulus limnaeus exhibit tolerance of anoxia that is substantially greater than any other vertebrate (Podrabsky

\footnotetext{
The authors declare no conflicts of interest associated with this work. Grant sponsor: National Institutes of Health, NHLBI; Grant number: R01HL095454.

${ }^{*}$ Correspondence to: Jason E. Podrabsky, Department of Biology, SRTC 246, Portland State University, 1719 SW 10th Ave., Portland, OR 972070751. Email: jpod@pdx.edu

Received 29 February 2012; Revised 11 May 2012; Accepted 5 June 2012

Published online in Wiley Online Library (wileyonlinelibrary.com). DOI: 10.1002/jez.1744
} 
et al., 2007, 2012). It is currently unclear how anoxia tolerance is supported from a physiological, biochemical, or molecular perspective in this species. However, it is likely that unique mechanisms operate to support this unparalleled tolerance of anoxia among vertebrates. In this study we demonstrate that embryos of A. limnaeus survive exposure to anoxia despite a rapid and severe drop in ATP levels that would induce necrotic and apoptotic cell death in the majority of vertebrate species.

A. limnaeus inhabits ephemeral ponds in regions of Venezuela that experience annual dry and rainy seasons (Hrbek et al., 2005). Populations survive the complete drying of the habitat through the presence of diapausing embryos that are drought tolerant (Wourms, '72a; Podrabsky et al., 2001). There are three distinct stages of diapause possible in annual killifish, named diapause I, II, and III (Wourms, '72b). Embryos of A. limnaeus routinely enter into diapause II and III, but rarely enter diapause I (Wourms, '72b; Podrabsky and Hand, '99). Diapause is a state of developmental arrest that precedes the onset of unfavorable environmental conditions, and thus embryos will enter dormancy even under conditions conducive to normal development (Hand, '91). Diapause in embryos of $A$. limnaeus is associated with a cessation of development, and a profound metabolic depression (Podrabsky and Hand, '99). Diapausing embryos exhibit indicators of positive cellular energetic status as evidenced by high levels of total adenylates, ATP/ADP ratios, and adenylate energy charge (AEC) (Podrabsky and Hand, '99). However, adenosine monophosphate (AMP) levels are elevated in diapausing embryos, which results in an increased AMP/ATP ratio consistent with activation of the AMP-activated protein kinase AMPK (Podrabsky and Hand, '99). AMPK is part of an ultrasensitive system for monitoring cellular energy changes and can be considered a metabolic "fuel gauge" (Hardie et al., '98). Thus, A. limnaeus embryos appear to conform to the general observation that cellular energy status is maintained in a moderate range during diapause (e.g., Hand et al., 2011), and there is very likely a coordinated downregulation of ATP production and consumption associated with entry into this state.

Embryos of A. limnaeus gain the ability to enter into a state of anoxia-induced quiescence as they develop toward and enter into diapause II (Podrabsky et al., 2007). The substantial tolerance of anoxia exhibited by diapause II embryos is maintained for several days of post-diapause II development, providing a window where the embryos are actively developing but still able to tolerate long periods without oxygen (Podrabsky et al., 2007). In fact, long-term anoxia tolerance peaks during diapause II with an $\mathrm{LT}_{50}$ of around 65 days (at $25^{\circ} \mathrm{C}$ ), and this level of anoxia tolerance is retained for at least 4 days of post-diapause II development (Podrabsky et al., 2007). Post-diapause II embryos exposed to anoxia cease development and reduce heart activity (Fergusson-Kolmes and Podrabsky, 2007), however the metabolic and energetic status of these embryos during exposure to anoxia has not yet been investigated. Based on data available for dormancy during diapause in this species (Podrabsky and Hand, '99) and data available for tissues in other vertebrate facultative anaerobes such as freshwater turtles and crucian carp (e.g., Buck et al., '93; Nilsson and Lutz, 2004; Stecyk et al., 2009), one would predict that levels of total adenylates should remain high, and cellular ATP levels will be defended in embryos of $A$. limnaeus during the initial transition into anoxia. In this article we show that in response to anoxia embryos of A. limnaeus experience a profound decrease in heat dissipation, and a rapid and dramatic decrease in ATP levels. This latter pattern is unusual among the vertebrates that can survive long-term anoxia.

\section{MATERIALS AND METHODS}

\section{Fish Husbandry and Embryo Collection}

Adult fish were housed in the Portland State University Aquatic Vertebrate Facility using previously published methods according to NIH guidelines under approval from the PSU IACUC (Podrabsky, '99; Machado and Podrabsky, 2007). Briefly, spawning pairs of fish were housed in $10 \mathrm{~L}$ aquaria in rack systems of 21 tanks connected to a common sump tank. Temperature of the system was maintained at $26 \pm 1{ }^{\circ} \mathrm{C}$. Embryos were collected twice weekly as described in Podrabsky ('99). For the duration of their development they were incubated at $25^{\circ} \mathrm{C}$ in the dark in embryo medium (10 mmol L ${ }^{-1} \mathrm{NaCl}, 0.14 \mathrm{mmol} \mathrm{L}{ }^{-1} \mathrm{KCl}, 2.15 \mathrm{mmol} \mathrm{L}^{-1}$ $\mathrm{MgCl}_{2}, 0.0013 \mathrm{mmol} \mathrm{L}^{-1} \mathrm{MgSO}_{4}, 0.8 \mathrm{mmol} \mathrm{L}^{-1} \mathrm{CaCl}_{2}$ ) containing $10 \mathrm{mg} \mathrm{L}^{-1}$ gentamycin sulfate (Podrabsky, '99).

\section{Breakage of Diapause II}

Diapause II was experimentally broken in embryos by exposure to a $14 \mathrm{hr}$ light: $10 \mathrm{hr}$ dark photoperiod at $30^{\circ} \mathrm{C}$ for $48 \mathrm{hr}$. Embryos were inspected daily and those found to have broken diapause on the same day were grouped together and used as one experimental replicate. Not all of the embryos break diapause synchronously, and thus a single exposure to the conditions listed above produces at least two cohorts of post-diapause II embryos that are developing synchronously.

\section{Developmental Stages}

Two developmental stages were chosen for this study based on their extreme tolerance to anoxia. Diapause II embryos 32-40 days post-fertilization were used to explore how diapausing embryos that are already dormant respond to anoxia. Embryos at 4 days post-diapause II (dpd) were chosen because they exhibit the same tolerance of anoxia as diapause II embryos, but are actively developing and have undergone major changes in morphology and physiology. These embryos are at the equivalent of Wourms' stage (WS) 36 (Wourms, '72a) and have a significantly higher metabolic rate compared to diapause II embryos (Podrabsky and Hand, '99). A number of embryological advances are associated with reaching WS 36 including: initiation of organogenesis, advanced cardiovascular development and a heart rate of over 
50 beats $\min ^{-1}$, increased neural complexity and the presence of eye pigmentation, and the expression of hemoglobin.

\section{Calorimetry}

Heat dissipation was measured at $25^{\circ} \mathrm{C}$ using a model 2277 thermal activity monitor (LKB, Bromma, Sweden) outfitted with a nanowatt amplifier. Embryos and media to equal a total volume of $2.5 \mathrm{~mL}$ were sealed into a $5 \mathrm{~mL}$ stainless steel ampule. An identical $5 \mathrm{~mL}$ ampule filled with aerobic embryo medium served as a reference. For aerobic conditions it was necessary to equilibrate the medium with a gas mixture of 40\% oxygen and 60\% nitrogen to avoid diffusion-limited oxygen supply to the embryos in the absence of stirring. The head-space of the ampule was purged with this gas mixture for $5 \mathrm{~min}$ prior to sealing of the ampule. Four replicate runs were performed on each developmental stage. For aerobic conditions 50 diapause II and 5 post-diapause II embryos were used for each replicate. This number of embryos produced a stable (diapause II) or increasing rate of heat dissipation (postdiapause II) in each replicate as would be expected under conditions where oxygen is not limiting. A larger number of embryos were used for each anoxic run, 190-210 embryos for diapause II embryos, and 20-70 embryos for the post-diapause II stage. For each replicate the aerobic rate was obtained first, and the ampule was then removed from the calorimeter. The medium was replaced with anoxic medium (purged with high purity nitrogen gas for $>1 \mathrm{hr}$ ), prior to reintroduction of the embryos for the anoxic run. Just prior to sealing the ampule for anoxic runs the head space was purged with nitrogen gas for 5 min to maintain anoxic conditions upon sealing of the ampule. Embryos were returned to the calorimeter and allowed to thermally equilibrate for $30 \mathrm{~min}$ prior to the resumption of data collection. Anoxic runs ranged in duration from 11.5 to $-21 \mathrm{hr}$ in length, depending on how long it took for the heat flow to reach a rate of change indistinguishable from instrument drift. Aerobic and anoxic heat dissipation values were calculated as the mean heat dissipation for the last $15 \mathrm{~min}$ of each run. The lowest values for embryo heat dissipation recorded under anoxia were approximately $1.7 \mu \mathrm{W}$, and blanks averaged within $0.2 \mu \mathrm{W}$ of zero.

\section{Determination of Phosphorylated Adenylate Compounds}

Embryos were exposed to anoxia in a Bactron III anaerobic chamber that maintains anoxia through the use of an anaerobic gas mixture $\left(5 \% \mathrm{H}_{2}, 5 \% \mathrm{CO}_{2}\right.$, balance $\left.\mathrm{N}_{2}\right)$ and a palladium catalyst (Sheldon Manufacturing, Cornelius, OR, USA). Prior to placing them in the chamber, embryos were rinsed three times with embryo medium previously purged with industrial grade nitrogen gas for $30 \mathrm{~min}$. The embryos (in $100 \times 15 \mathrm{~mm}$ plastic culture dishes) were then placed in the chamber through a pass box following three cycles of vacuum to $-18 \mathrm{in} \mathrm{Hg}$ and replacement of the gas with anaerobic gas mixture. Once in the anaerobic chamber the embryos were transferred to culture dishes preequilibrated in the anaerobic chamber for at least 5 days. This step is necessary to ensure that oxygen does not leach into the embryo medium from the original culture dishes. Embryo medium was then replaced with pre-equilibrated anoxic medium (purged with industrial grade nitrogen gas for $30 \mathrm{~min}$ and allowed to equilibrate to the conditions in the anaerobic chamber for at least $24 \mathrm{hr}$ ). Embryos were incubated at $25^{\circ} \mathrm{C}$ using the Bactron's internal incubator. Anoxic samples were transferred into microcentrifuge tubes within the Bactron chamber, and sealed prior to removal from the chamber. Samples were then quickly weighed and immediately frozen in liquid nitrogen prior to preparation of acid extracts.

Perchloric acid (PCA) extracts of embryos were prepared as previously described (Podrabsky and Hand, '99). Briefly, groups of 50-200 embryos were homogenized in microcentrifuge tubes in 6 volumes (by weight) of ice-cold 1 N PCA containing 5 mM EDTA using an Ultraturrax homogenizer (IKA, Wilmington, NC, USA). The homogenates were allowed to sit on ice for $15 \mathrm{~min}$ prior to centrifugation at $16,000 \mathrm{~g}$ for $30 \mathrm{~min}$. The supernatant was neutralized by the addition of ice-cold $5 \mathrm{M}$ potassium carbonate ( $9 \%$ of the original volume of PCA added). Extracts were stored at $-80^{\circ} \mathrm{C}$ until analysis.

Separation and quantification of phosphorylated adenylate compounds were performed using a Dionex HPLC system (Dionex, Sunnyvale, CA, USA), as described previously (Menze et al., 2005). Separation was achieved using a Synergy $4 \mu \mathrm{m}$ Hydro RP 80A column (Phenomenex, Torrance, CA, USA) and a linear gradient $\left(1 \mathrm{~mL} \min ^{-1}\right.$ flow rate, $30^{\circ} \mathrm{C}$ ) between acetonitrile and $50 \mathrm{mM}$ $\mathrm{K}_{2} \mathrm{HPO}_{4} / \mathrm{KH}_{2} \mathrm{PO}_{4}$ (pH 6.2) containing $10 \mathrm{mM}$ tetrabutylammonium bisulfate. Following $15 \mathrm{~min}$ of elution with the above buffer, acetonitrile was increased from $0 \%$ to $25 \%$ over $40 \mathrm{~min}$. Effluent absorbance was monitored at wavelengths between 190 and $390 \mathrm{~nm}$ with a photodiode array detector. Compounds were identified by comparison with retention times of standards, as well as by analysis of the given peak spectrum from a recorded three-dimensional field with Chromeleon software (Dionex). Concentration of nucleotides was determined from a measurement of peak area at 260-nm wavelength, via interpolation with a linear calibration curve. Values are expressed in nmol embryo ${ }^{-1}$. Estimates of cellular concentrations can be made by taking into account that only $10-15 \%$ of the mass of the embryos is composed of metabolically active cells, the rest being yolk, extra-embryonic fluid, and egg envelope.

\section{Statistical Analyses}

Analysis of variance (ANOVA) was used to compare mean rates of heat dissipation and levels of phosphorylated adenylates (general linear model, IBM SPSS Statistics, version 19). For comparisons of heat dissipation data, each treatment and developmental stage was treated as a separate sample, allowing for comparisons within and between developmental stages. For comparisons of phosphorylated adenylate compounds, analyses were performed on each compound separately, and post hoc comparisons made comparing levels at different times in anoxia to the control values 
at $t=0$ using Dunnett's $t$-test (two-sided). For all comparisons, significance was set at $P<0.05$.

\section{RESULTS}

\section{Metabolic Depression}

Embryos exposed to anoxia experience a profound decrease in heat dissipation and reach extremely low levels of heat flow within the first hours of exposure (Fig. 1). Heat dissipation rates in diapause II embryos exposed to anoxia (11.4 $\pm 3 \mathrm{nW}$ embryo $^{-1}$; mean \pm s.e.m., $n=4$ ) are statistically indistinguishable from values obtained from aerobic embryos $\left(57.4 \pm 10 \mathrm{nW}\right.$ embryo $^{-1}$, ANOVA, Tukey's $P>0.05$ ), although the anoxic embryos average rate of heat dissipation is $20 \%$ of aerobic values (Fig. 2). In contrast, post-diapause II embryos experience a profound decrease in heat dissipation from $767.9 \pm 28 \mathrm{nW}$ embryo $^{-1}$ to $30.2 \pm 5 \mathrm{nW}$ embryo $^{-1}$ when exposed to anoxia (ANOVA, Tukey's $P<0.001$ ). This amounts to a decrease in heat dissipation to about $4 \%$ of aerobic values within $12-14 \mathrm{hr}$ of exposure to anoxia (Figs. 1 and 2). Interestingly, heat dissipation rates in anoxic post-diapause II embryos are indistinguishable from aerobic and anoxic heat dissipation in diapause II embryos (Fig. 2; ANOVA, Tukey's $P>0.05$ ).

\section{Cellular Energy Status}

Post-diapause II embryos have significantly higher levels of total adenylates (0.55 $\pm 0.03 \mathrm{nmol}$ embryo $^{-1}$; mean \pm s.e.m., $n=3$ )

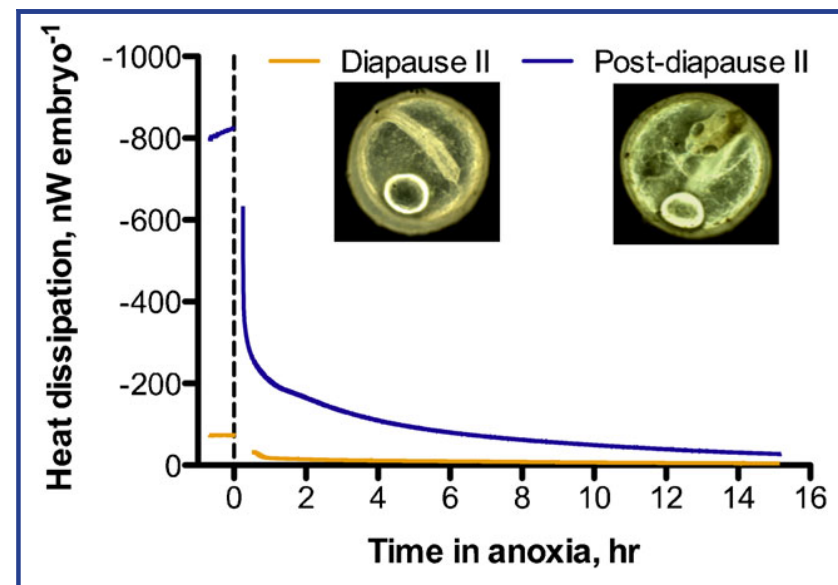

Figure 1. Representative heat dissipation data for aerobic and anoxic embryos of $A$. limnaeus. The dashed line indicates the initiation of anoxic conditions, and the gap in the tracing is due to removal and re-equilibration of the ampule containing the embryos following establishment of anoxic conditions. The last $15 \mathrm{~min}$ of each aerobic and anoxic run were used to extract data for the heat dissipation data presented in Figure 2.

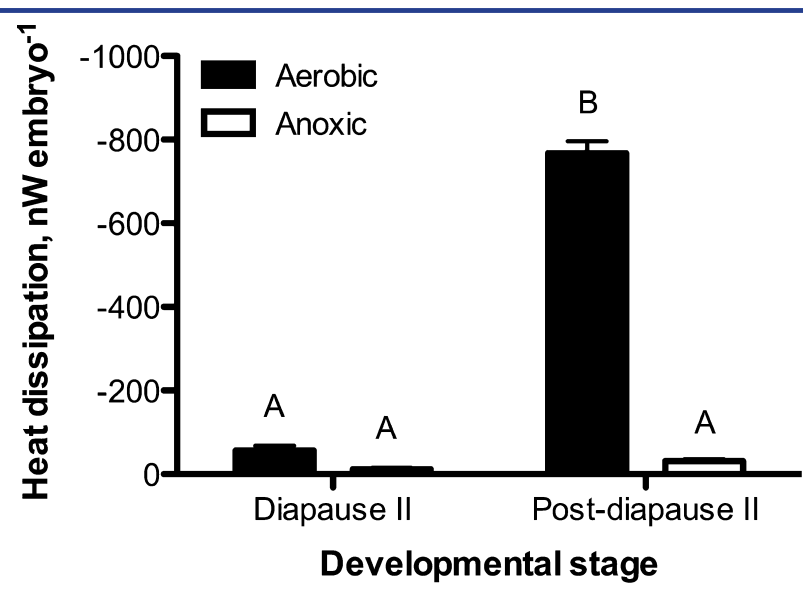

Figure 2. Rate of heat dissipation in diapause II and post-diapause II embryos under aerobic and anoxic conditions. Bars represent the mean \pm s.e.m. $(n=4)$. Bars with different letters are statistically different (ANOVA, Tukey's post hoc, $P<0.001$ ).

and ATP (0.46 \pm 0.02 nmol embryo $\left.{ }^{-1}\right)$ under aerobic conditions when compared to diapause II embryos (total adenylates $=0.3$

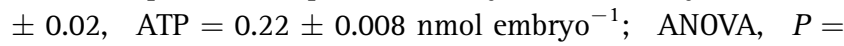
0.002 for total adenylates, $P=0.001$ for ATP). Levels of ADP are similar in both developmental stages under aerobic conditions with mean values of $0.085 \pm 0.009 \mathrm{nmol} \mathrm{embryo}^{-1}$ for postdiapause II embryos and $0.067 \pm 0.01 \mathrm{nmol}$ embryo $^{-1}$ in diapause II embryos (ANOVA, $P=0.287$ ). AMP is similarly low in both developmental stages under aerobic conditions, $0.005 \pm 0.005$ for post-diapause II and $0.014 \pm 0.007 \mathrm{nmol}$ embryo $^{-1}$ for diapause II (ANOVA, $P=0.398$ ). A large-scale drop in ATP occurs in both developmental stages under exposure to anoxia (Fig. 3). Diapause II embryos experience a four-fold decrease in ATP content after $48 \mathrm{hr}$ of anoxia reaching values as low as $0.054 \pm 0.002 \mathrm{nmol}^{\text {embryo }}{ }^{-1}$, while in post-diapause II embryos ATP levels drop by 8.3-fold to a very similar value of $0.056 \pm 0.006 \mathrm{nmol}$ embryo $^{-1}$. ADP remains unchanged upon exposure to anoxia at values around $0.10 \mathrm{nmol}$ embryo $^{-1}$ in both developmental stages. However, AMP increases by 6.5 -fold in diapause II embryos to $0.089 \pm 0.001 \mathrm{nmol}$ embryo $^{-1}$, and 36 fold in post-diapause II embryos to $0.19 \pm 0.005 \mathrm{nmol} \mathrm{embryo}^{-1}$. The total adenylate pool remains unaltered by exposure to $48 \mathrm{hr}$ of anoxia in diapause II embryos at $0.24 \pm 0.007 \mathrm{nmol}^{\text {embryo }}{ }^{-1}$. In contrast, post-diapause II embryos experience a $40 \%$ decrease in total adenylates after $48 \mathrm{hr}$ of anoxia to $0.34 \pm 0.004 \mathrm{nmol}$ embryo $^{-1}$. These shifts in adenylates lead to significant decreases in AEC and ATP/ADP ratios, and a significant increase in the AMP/ATP ratio within the first $14 \mathrm{hr}$ of anoxia for both developmental stages (Fig. 4). Diapause II embryos experience a decline in AEC from $0.84 \pm 0.03$ to $0.43 \pm 0.001$ and in ATP/ADP 


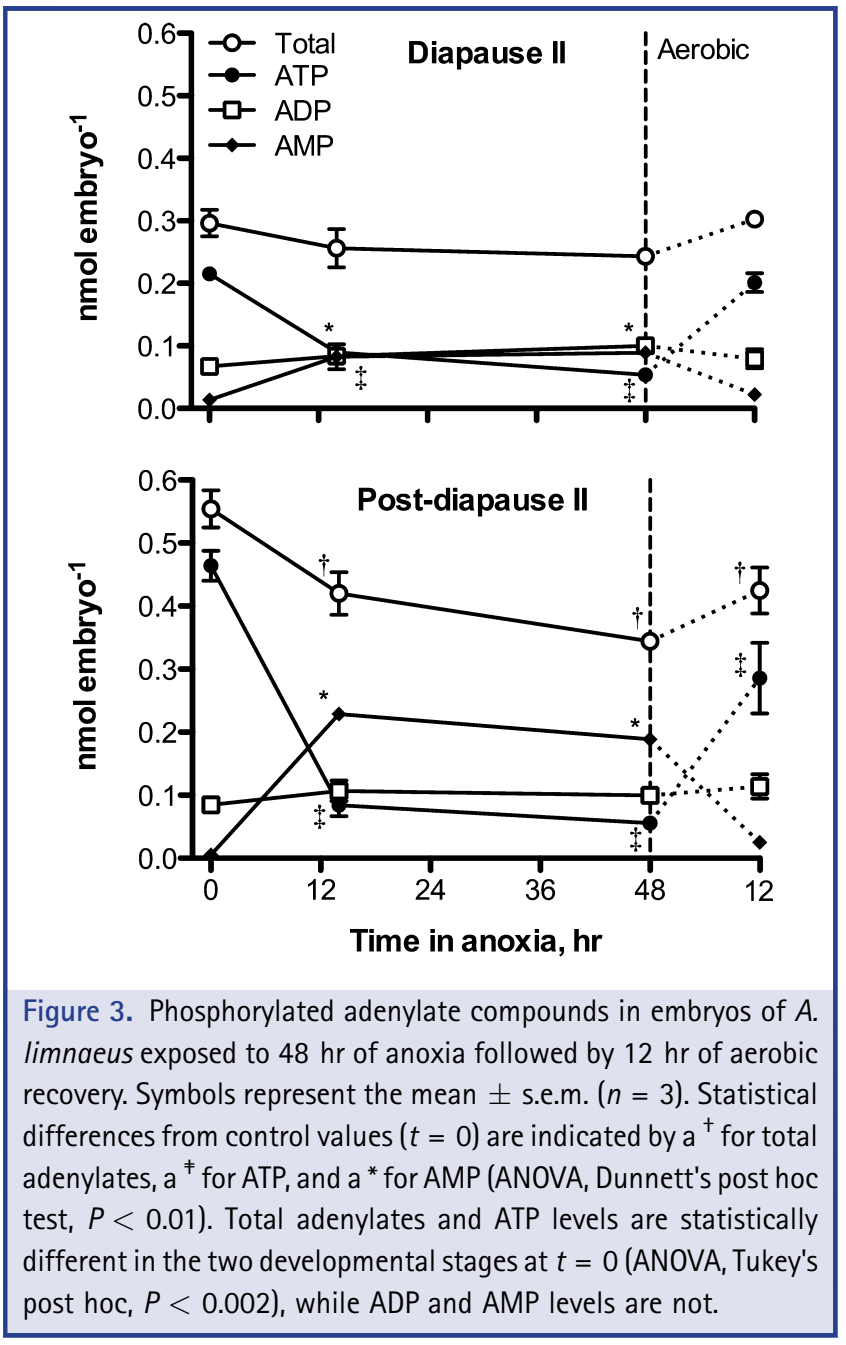

ratios from $3.3 \pm 0.36$ to $0.55 \pm 0.08$ after $48 \mathrm{hr}$ of anoxia. In post-diapause II embryos, $48 \mathrm{hr}$ of anoxia causes an even greater decrease in AEC from $0.91 \pm 0.01$ to $0.31 \pm 0.01$ and in ATP/ADP ratios from $5.6 \pm 0.4$ to $0.57 \pm 0.08$. AMP/ATP ratios increase substantially from $0.064 \pm 0.03$ to $1.7 \pm 0.05$ in diapause II embryos and from $0.012 \pm 0.01$ to $3.4 \pm 0.4$ in post-diapause II embryos.

Diapause II embryos recover more quickly from $48 \mathrm{hr}$ of anoxia than do post-diapause II embryos (Figs. 3 and 4). All three species of adenylates return to control values as do all three metrics of cellular energy status after $12 \mathrm{hr}$ of aerobic recovery in diapause II embryos (Figs. 3 and 4). In post-diapause II embryos, ADP and AMP return to near control values after $12 \mathrm{hr}$ of aerobic recovery, while ATP remains 40\% below control values. This results in a failure of the ATP/ADP ratio to return to control values. In addition, the pool of total adenylates is $23 \%$ lower than levels prior to exposure to anoxia, suggesting the likely loss of adenylates

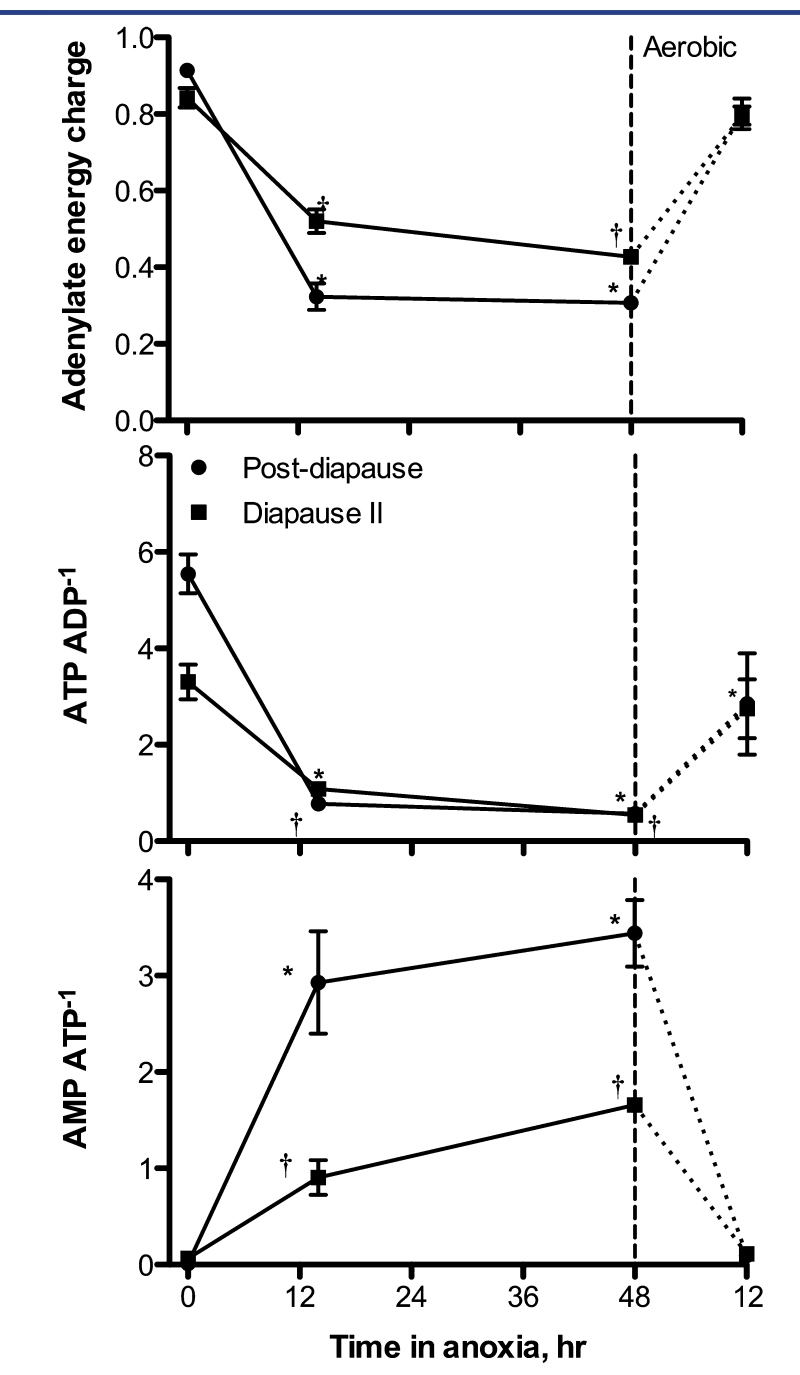

Figure 4. Measures of energetic status for embryos of $A$. limnaeus exposed to anoxia followed by $12 \mathrm{hr}$ of aerobic recovery. Symbols are means \pm s.e.m. $(n=3)$. Statistically significant differences from values at $t=0$ are indicated by a ${ }^{*}$ for post-diapause II, and a ${ }^{+}$for diapause II embryos (ANOVA, Dunnett's post hoc, $P<0.01$ ).

through degradation to adenosine or other compounds (Figs. 3 and 4).

\section{DISCUSSION}

Developmental Stage-Specific Responses to Anoxia

Exposure to anoxia causes a significant decline in heat dissipation in post-diapause II embryos, consistent with data from other species of vertebrate facultative anaerobes (Hochachka et al., '96). In contrast, diapause II embryos do not experience a statistically significant decline in heat dissipation during anoxia. These data 
suggest that diapause II embryos likely support a large percentage of their metabolism using anaerobic pathways even under aerobic conditions. This conclusion is consistent with the high $\mathrm{C}: \mathrm{R}$ ratios (Podrabsky and Hand, '99) and the low levels of oxidative capacity observed in diapause II embryos (Chennault and Podrabsky, 2010) and mitochondria isolated from diapause II embryos (Duerr and Podrabsky, 2010). Such a phenotype of aerobic glycolysis is similar to that seen in some types of hard tumors (Lunt and Vander Heiden, 2011).

Both diapausing and post-diapausing embryos have similar rates of heat dissipation during anoxia, despite large differences under aerobic conditions. The convergence of the two developmental stages on a similar heat flow during anoxia may indicate a common metabolic phenotype for survival of long-term anoxia in this species. It may also indicate that aerobic diapausing embryos have already reduced energy flow to the minimum levels necessary to maintain viability. More detailed studies of heat flow and accumulation of metabolic end-products during the first 24-48 hr of anoxia would be required to better define the metabolic rate of anoxic embryos and the pathways used to support this metabolism. However, the similar levels of heat dissipation in the two developmental stages, coupled with similar levels of ATP may indicate a restructuring of metabolism that is common to both developmental stages.

\section{Levels of ATP, Metabolic Depression, and Cell Death}

A great deal of effort has been spent investigating the molecular mechanisms that support tolerance of hypoxia and anoxia in animal species (Hand and Hardewig, '96; Hand, '98; Krumschnabel, 2000; Hochachka and Somero, 2002). From these data, a suite of characters has been assembled that appear to separate anoxia tolerant from intolerant animals. At the heart of this model for anoxia tolerance is the ability to reversibly suppress cellular metabolism through a coordinated downregulation of energy consuming and energy producing pathways, such that the energetic status of the cells is maintained. This model is typified by facultative vertebrate anaerobes such as freshwater turtles and the crucian carp (Hochachka et al., '96; Lutz and Nilsson, '97; Nilsson and Lutz, 2004). Consistent with this model, embryos of $A$. limnaeus experience a profound arrest of heat flow during exposure to anoxia. However, surprisingly ATP levels plummet rapidly in anoxic embryos of $A$. limnaeus, and all indicators of cellular energetic status indicate a lack of tight coupling between ATP production and consumption during the transition into anoxia. Thus, the annual killifish embryo, the most anoxia tolerant vertebrate, deviates from other vertebrate facultative anaerobes by experiencing a rapid and severe decrease in ATP during the initial transition into anoxia. The importance of this major difference in the timing and severity of ATP loss is not yet clear, but has many implications for the survival of vertebrate cells faced with limited ability to produce ATP and support "normal" rates of ATP turnover.
One caveat that should be considered is that the methods employed in this study yield total and not free levels of phosphorylated adenylates. These values are the best estimates that can currently be reported in this system due to a large interfering peak that obscures the adenylate resonances using nuclear magnetic resonance spectroscopy (Podrabsky, unpublished). Importantly, it is very unlikely that knowing the free levels of adenylates would significantly alter the results or interpretations in this study. The level of free adenylates will always be lower than the total levels, and thus in the case of ATP, the effective levels of cellular ATP may be even lower than reported here, and thus would not change any major interpretations of the data. In contrast, the drastic increase in total AMP is very likely to yield a biological effect, and thus while the actual magnitude of the increase may be over-estimated, the biological consequences are not likely to change. For ADP, the lack of a change in concentration suggests no change in activity, if we assume that the ratio of free to total ADP does not change during anoxia.

Patterns of ATP levels in animals exposed to anoxia appear to fall into four major categories when viewed as a function of maximal survival time in anoxia (Fig. 5). First, there are a number of invertebrate species that experience an initial loss of ATP, but then reach a new steady state level of ATP during long-term anoxia (Fig. 5A). These animals typically have survival times in days or months at low temperatures $\left(\leq 10^{\circ} \mathrm{C}\right)$ and for several days near room temperature. In contrast to embryos of $A$. limnaeus, other vertebrate facultative anaerobes such as goldfish, crucian carp, and freshwater turtles appear to maintain high ATP levels during the initial transition into anoxia (Fig. 5B, C). However, tissue-specific responses appear to follow this initial defense of ATP levels (Fig. 5B); muscle maintains high levels of ATP during long-term anoxia, heart reaches a new steady-state level around $50-60 \%$ of initial values, and liver experiences an eventual major decline in ATP levels (Jackson et al., '95; Stecyk et al., 2009). The third major pattern is a nearly continual and steady loss of ATP until death as illustrated by frog and rat brain (Fig. 5C). However, it is noteworthy that in several tissues of the common frog Rana temporaria, ATP declines to as low as 15\% of control aerobic values over a $2 \mathrm{hr}$ period of anoxia (Wegener et al., '86; Wegener, '88), but then returns to control values after $2 \mathrm{hr}$ of aerobic recovery (Wegener, '88). Thus the ATP decline is reversible, so long as the maximal survival time for this species is not exceeded. The fourth, and perhaps most striking pattern, is an initial and dramatic drop of ATP to low levels during the transition into anoxia. This pattern is illustrated by embryos of $A$. limnaeus, and by embryos of the brine shrimp Artemia franciscana (Fig. 5A, C). Importantly, the fourth strategy of an initial and large drop in ATP levels is associated with extreme tolerance of anoxia in both species.

The benefit of a large drop in ATP levels is not readily apparent, while the negative consequences appear to be manifold. In $A$. 

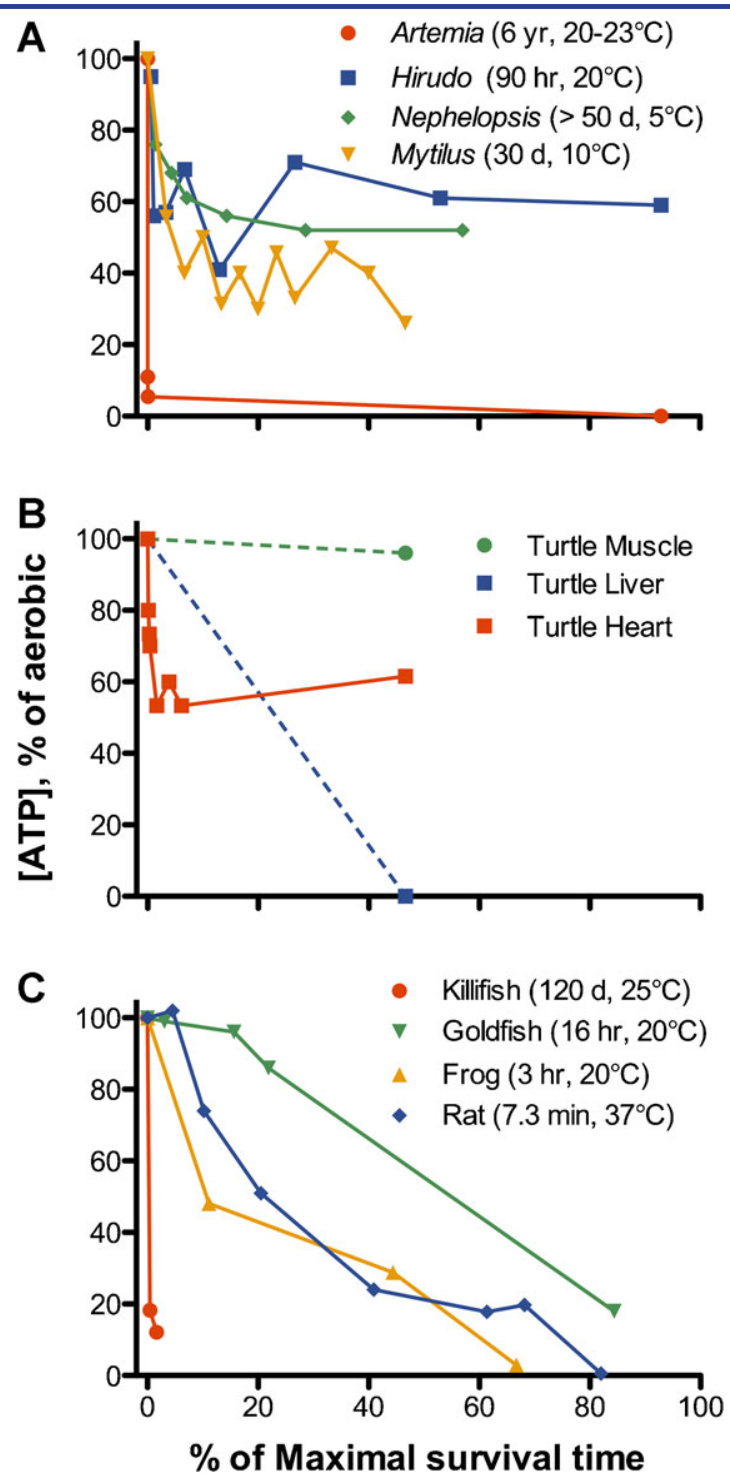

Figure 5. The relationship between depletion of ATP levels and survival of anoxia in animals. (A) Invertebrate species with high tolerances of anoxia, Artemia fransciscana (brine shrimp, early anoxia ATP levels from Anchordoguy and Hand, '94; survival time and longterm anoxia ATP levels from Warner and Clegg, 2001), Hirudo medicinalis (leech, Zebe et al., '81) Nephelopsis obscura (leech, Reddy and Davies, '93 for ATP levels, survival time from Davies et al., '87), Mytilus galloprovincialis (mussel, Isani et al., '95). (B) Tissues of anoxic turtles (Chrysemys picta) exposed to anoxia at $3-5^{\circ} \mathrm{C}$ (Jackson et al., '95; Stecyk et al., 2009 for heart). Survival time estimated at 180 days at $3^{\circ} \mathrm{C}$ (Ultsch and Jackson, '82). (C) Levels of ATP in brain tissue of goldfish Carassius auratus (van den Thillart, '82), frog Rana pipiens (Lutz and Reiners, '97), 10-day-old rat Rattus norvegicus (Lolly and Samson, '62 for ATP levels; Adolph, '69 for survival), and post-diapause II embryos of $A$. limnaeus (this study). franciscana, the drop in ATP is associated with a significant drop in intracellular $\mathrm{pH}$. In Artemia, the drop in $\mathrm{pH}_{i}$ is known to induce many of the changes associated with anoxia-induced quiescence in this system, including arrestment of carbohydrate metabolism. However, large changes in $\mathrm{pH}_{i}$ are not typically tolerated by animal cells, and thus this strategy could have limited applicability. There are also many allosteric effects on metabolic enzymes that would be associated with this drop in the concentration of ATP. Some have argued that the decreased free energy of ATP hydrolysis associated with major decreases in levels of ATP relative to ADP would be detrimental to the cell (e.g., Fiolet et al., '84; Tian and Ingwall, '96; Ingwall and Weiss, 2004). In these studies, it appears that the ability to maintain cellular ion gradients, especially intracellular calcium via the activity of calcium ATPases, is tightly linked to the free energy of ATP hydrolysis, and levels below about $52-53 \mathrm{~kJ} \mathrm{~mol}^{-1}$ are not tolerated in cardiac myocytes. Levels of free inorganic phosphate are currently unknown in embryos of A. limnaeus, and thus it is not possible to estimate the free energy of ATP hydrolysis. However, we hypothesize that the reduced amount of ATP present in anoxic embryos of $A$. limnaeus leads to a reduction in the free energy of hydrolysis for ATP that is still sufficient to support maintenance of critical cellular ion gradients.

Major decreases in cellular ATP levels are often associated with cell death, both through necrotic and apoptotic pathways (Richter et al., '96; Hand and Menze, 2008). However, the requirement for high levels of ATP to support cell survival is a point of some contention. In many tissues and situations a fall in ATP is an excellent sign of impending cell death (see Fig. 5C), but it may not be the cause. For example, a few studies employing metabolic inhibitors on quiescent cells (induced by removal of growth factors) have reported survival of cells in culture despite severely reduced (sometimes less than 10\% of control) levels of ATP and an associated drop in relevant indicators of cellular energetic status (Live and Kaminskas, '75; Venkatachalam et al., '88). It is worth emphasizing that in both of these studies the cells were quiescent, and perhaps withdrawal from the cell cycle is one prerequisite for surviving depletion of ATP stores. In addition, even cells with substantial tolerance of anoxia (goldfish, Fig. 5C) experience a loss of ATP levels under prolonged anoxia in a manner very similar to that of anoxia sensitive species such as rats. Thus, a loss of ATP may signal impending cell death, or even be the cause of cell death in active cells with high metabolic demands, but in situations where ATP turnover is limited, a severe decline in ATP levels and cellular energetic balance may be tolerated.

\section{Broader Implications}

It is intriguing that two of the most anoxia tolerant animals, embryos of A. franciscana and A. limnaeus do not defend cellular levels of ATP when faced with anoxia. Thus, it is clear that maintenance of high levels of cellular ATP is not a prerequisite for cellular survival, and the importance of a coordinated 
downregulation of catabolic and anabolic pathways has perhaps been over-stressed in the literature. In addition, data from this study and others using quiescent (growth factor deprived) cells suggest that the prerequisite for survival of energy limitation is reduced metabolic demand. In this case, then loss of ATP and a subsequent increase in AMP observed in embryos of $A$. limnaeus would be beneficial through activation of AMPK and allosteric regulation of key metabolic enzymes. The significance of this finding is not yet completely clear, but it does challenge one of the central tenets of the requirements for surviving oxygen limitation as outlined by Hochachka et al. ('96). It is interesting that both $A$. limnaeus and $A$. franciscana survive prolonged anoxia as embryos, and perhaps it is something inherent in the metabolism of development that causes or allows the depletion of ATP levels associated with anoxic quiescence. The advantages of a lowered ATP level are not readily apparent, while the disadvantages are many. The fact that the vast majority of animal cells cannot recover from such a drastic loss of ATP, reinforces the potential importance of this finding. Further research into the mechanisms that support anoxic metabolism in cells of A. limnaeus embryos is very likely to highlight mechanisms for cell survival that have not been previously studied in vertebrate cells.

\section{ACKNOWLEDGMENT}

This work was supported by a NIH National Heart Lung and Blood Institute grant to J.E.P. (R01HL095454).

\section{LITERATURE CITED}

Adolph EF. 1969. Regulations during survival without oxygen in infant mammals. Respir Physiol 7:356-368.

Anchordoguy TJ, Hand SC. 1994. Acute blockage of the ubiquitin-mediated proteolytic pathway during invertebrate quiescence. Am J Physiol Regul Integr Comp Physiol 267:R895R900.

Buck LT, Land SC, Hochachka PW. 1993. Anoxia-tolerant hepatocytes: model system for study of reversible metabolic suppression. Am J Physiol Regul Integr Comp Physiol 265:R49-R56.

Chennault T, Podrabsky JE. 2010. Aerobic and anaerobic capacities differ in embryos of the annual killifish Austrofundulus limnaeus that develop on alternate developmental trajectories. J Exp Zool A 313A:587-596.

Davies RW, Yang T, Wrona FJ. 1987. Inter- and intra-specific differences in the effects of anoxia on Erpobdellid leeches using static and flow-through systems. Ecology 10:149-153.

Duerr JM, Podrabsky JE. 2010. Mitochondrial physiology of diapausing and developing embryos of the annual killifish Austrofundulus limnaeus: implications for extreme anoxia tolerance. J Comp Physiol B 180:991-1003.

Fergusson-Kolmes L, Podrabsky JE. 2007. Differential effects of anoxia on heart rate in developmental stages of the annual killifish Austrofundulus limnaeus that differ in their tolerance of anoxia. J Exp Zool A 307A:419-423.
Fiolet JWT, Baartscheer A, Schumacher CA, Coronel R, ter Welle HF. 1984. The change in free energy of ATP hydrolysis during global ischemia and anoxia in the rat heart. J Mol Cell Card 16:1023-1036.

Hand SC. 1991. Metabolic dormancy in aquatic invertebrates. In: Gilles $\mathrm{R}$, editor. Advances in comparative and environmental physiology. Berlin: Springer Verlag. p 1-50.

Hand SC. 1998. Quiescence in Artemia franciscana embryos: reversible arrest of metabolism and gene expression at low oxygen levels. J Exp Biol 201:1233-1242.

Hand SC, Hardewig I. 1996. Downregulation of cellular metabolism during environmental stress: mechanisms and implications. Annu Rev Physiol 58:539-563.

Hand SC, Menze MA. 2008. Mitochondria in energy-limited states: mechanisms that blunt the signaling of cell death. J Exp Biol 211:1829-1840.

Hand SC, Menze MA, Borcar A, Patil Y, Covi JA, Reynolds JA, et al. 2011. Metabolic restructuring during energy-limited states: insights from Artemia franciscana embryos and other animals. J Insect Physiol 57:584-594.

Hardie DG, Carling D, Carlson M. 1998. The AMP-activated/SNF1 protein kinase subfamily: metabolic sensors of the eukaryotic cell? Annu Rev Biochem 67:821-855.

Hochachka PW. 1986. Defense strategies against hypoxia and hypothermia. Science 231:234-241.

Hochachka PW, Somero GN. 2002. Biochemical adaptation: mechanism and process in physiological evolution. New York: Oxford University Press.

Hochachka PW, Buck LT, Doll CJ, Land SC. 1996. Unifying theory of hypoxia tolerance: molecular/metabolic defense and rescue mechanisms for surviving oxygen lack. Proc Natl Acad Sci USA 93:9493-9498.

Hrbek T, Taphorn DC, Thomerson JE. 2005. Molecular phylogeny of Austrofundulus Myers (Cyprinodontiformes: Rivulidae), with revision of the genus and the description of four new species. Zootaxa 825:1-39.

Ingwall JS, Weiss RG. 2004. Is the failing heart energy starved?: on using chemical energy to support cardiac function. Circ Res 95:135145.

Isani G, Cattani O, Zurzolo M, Pagnucco C, Cortesi P. 1995. Energy metabolism of the mussel, Mytilus galloprovincialis, during longterm anoxia. Comp Biochem Physiol B 110B:103-113.

Jackson DC, Warburton SJ, Meinertz EA, Lawler RG, Wasser JS. 1995. The effect of prolonged anoxia at $3^{\circ} \mathrm{C}$ on tissue high energy phosphates and phosphodiesters in turtles: a ${ }^{31} \mathrm{P}-\mathrm{NMR}$ study. $\mathrm{J}$ Comp Physiol B 165:77-84.

Jibb LA, Richards JG. 2008. AMP-activated protein kinase activity during metabolic rate depression in the hypoxic goldfish, Carassius auratus. J Exp Biol 211:3111-3122.

Krumschnabel G. 2000. Cellular and molecular basis of anoxiatolerance and -intolerance in vertebrates: comparative studies using hepatocytes from goldfish and trout. Recent Res Dev Comp Biochem Physiol 1:1-11. 
Live TR, Kaminskas E. 1975. Changes in adenylate energy charge in Ehrlich ascites tumor cells deprived of serum, glucose, or amino acids. J Biol Chem 250:1786-1789.

Lolly RN, Samson FE Jr. 1962. Cerebral high-energy compounds: changes in anoxia. Am J Physiol 202:77-79.

Lunt SY, Vander Heiden MG. 2011. Aerobic glycolysis: meeting the metabolic requirements of cell proliferation. Annu Rev Cell Dev Biol 27:441-464.

Lutz PL, Nilsson GE. 1997. Contrasting strategies for anoxic brain survival-glycolysis up or down. J Exp Biol 200:411-419.

Lutz PL, Reiners R. 1997. Survival of energy failure in the anoxic frog brain: delayed release of glutamate. J Exp Biol 200:2913-2917.

Machado BE, Podrabsky JE. 2007. Salinity tolerance in diapausing embryos of the annual killifish Austrofundulus limnaeus is supported by exceptionally low water and ion permeability. J Comp Physiol B 177:809-820.

Menze MA, Clavenna MJ, Hand SC. 2005. Depression of cell metabolism and proliferation by membrane-permeable andimpermeable modulators: role for AMP-to-ATP ratio. Am J Physiol Regul Integr Comp Physiol 288:R501-R510.

Nilsson GE, Lutz PL. 2004. Anoxia tolerant brains. J Cereb Blood Flow Metab 24:475-486.

Podrabsky JE. 1999. Husbandry of the annual killifish Austrofundulus limnaeus with special emphasis on the collection and rearing of embryos. Environ Biol Fishes 54:421-431.

Podrabsky JE, Hand SC. 1999. The bioenergetics of embryonic diapause in an annual killifish, Austrofundulus limnaeus. J Exp Biol 202:2567-2580.

Podrabsky JE, Carpenter JF, Hand SC. 2001. Survival of water stress in annual fish embryos: dehydration avoidance and egg envelope amyloid fibers. Am J Physiol Regul Integr Comp Physiol 280:R123R131.

Podrabsky JE, Lopez JP, Fan TW-M, Higashi R, Somero GN. 2007. Extreme anoxia tolerance in embryos of the annual killifish Austrofundulus limnaeus: insights from a metabolomics analysis. J Exp Biol 210:2253-2266.

Podrabsky JE, Riggs CL, Duerr JM. 2012. Anoxia tolerance during vertebrate development. Insights from studies on the annual killifish Austrofundulus limnaeus. In: Padilla P, editor. Anoxia. Rijeka, Croatia: InTech.
Reddy DC, Davies RW. 1993. Metabolic adaptations by the leech Nephelopsis obscura during long-term anoxia and recovery. J Exp Zool 265:224-230.

Richter C, Schweizer M, Cossarizza A, Franceschi C. 1996. Control of apoptosis by cellular ATP level. FEBS Lett 378:107-110.

Stecyk JAW, Bock C, Overgaard J, Wang T, Farrell AP, Pörtner H-0. 2009. Correlation of cardiac performance with cellular energetic components in the oxygen-deprived turtle heart. Am J Physiol Regul Integr Comp Physiol 297:R756-R768.

Storey KB, Storey JM. 1990. Metabolic rate depression and biochemical adaptation in anaerobiosis, hibernation and estivation. Q Rev Biol 65:145-174.

Tian R, Ingwall JS. 1996. Energetic basis for reduced contractile reserve in isolated rat hearts. Am J Physiol Heart Circ Physiol 270:H1207H1216.

Ultsch GR, Jackson DC. 1982. Long-term submergence at $3^{\circ} \mathrm{C}$ of the turtle, Chrysemys picta bellii in normoxic and severely hypoxic water I. Survival, gas exchange, and acid-base status. J Exp Biol 96:11-28. van den Thillart G. 1982. Adaptations of fish energy metabolism to hypoxia and anoxia. Mol Physiol 2:49-61.

Venkatachalam MA, Patel YJ, Kreisberg Jl, Weinberg JM. 1988. Energy thresholds that determine membrane integrity and injury in a renal epithelial cell line (LLC-PK1). J Clin Invest 81:745-758.

Warner AH, Clegg JS. 2001. Diguanosine nucleotide metabolism and the survival of artemia embryos during years of continuous anoxia. Eur J Biochem 268:1568-1576.

Wegener G. 1988. Oxygen availability, energy metabolism, and metabolic rate in invertebrates and vertebrates. In: Acker $\mathrm{H}$, editor. Oxygen sensing in tissues. Berlin: Springer-Verlag. p 13-35.

Wegener G, Michel R, Thuy M. 1986. Anoxia in lower vertebrates and insects: effects on brain and other organs. Zool Beitr 30:103-124.

Wourms JP. 1972a. Developmental biology of annual fishes I. Stages in the normal development of Austrofundulus myersi Dahl. J Exp Zool 182:143-168.

Wourms JP. 1972b. The developmental biology of annual fishes. III. Pre-embryonic and embryonic diapause of variable duration in the eggs of annual fishes. J Exp Zool 182:389-414.

Zebe E, Salge U, Wiemann C, Wilps H. 1981. The energy metabolism of the leech Hirudo medicinalis in anoxia and muscular work. J Exp Zool 218:157-163. 